\title{
I'm sorry you are such an arsehole: (non-)canonical apologies and their implications for (im)politeness
}

\begin{abstract}
I report on a study into how native British English speakers ( $\mathrm{N}=78)$ respond to various instances of I'm sorry played to them in an experimental setting. The test items vary in terms of what the speaker is 'sorry' for, but are controlled such that the intonation of I'm sorry is kept the same throughout and the recordings are all produced by the same speaker. The results present some challenges for our current thinking about (im)politeness. In particular, examples which we could classify as 'verbal formula mismatches' (Culpeper, 2011: 174) such as I'm sorry you are such an arsehole are unexpectedly treated by a significant minority of respondents as being 'proper' apologies. I explore how we can account for this type of response and argue that Jucker \& Taavitsainen's (2008:6) suggestion that speech acts are 'fuzzy concepts' which 'require a prototype approach' is a productive one. I outline the parameters along which apologies can be more or less prototypical, including the identifiability of the offence and the speaker's perceived attitude towards it.
\end{abstract}

\subsection{Introduction}

Utterances where there is a clash between usually polite and impolite messages such as the titular I'm sorry you are such an arsehole have been discussed by a number of politeness scholars in recent years (e.g. Culpeper's 2011:174f verbal formula mismatches; Aijmer, 2015 on please used non-canonically; Leech's, 2014: 238f attitude clashes; Taylor, 2016: chapter 2 on im/politeness mismatch). Such examples are of interest because they present a challenge for our accounts of (im)politeness - if a speaker wishes to be impolite, then why pepper their talk with canonically polite expressions? ${ }^{1}$

In this paper, I move away from thinking about the intention behind such utterances, instead considering how they are interpreted by hearers. I report on a study which saw respondents asked to rate how apologetic a speaker was (amongst other things) in response to a number of utterances beginning with I'm sorry - some typical apologies, and others where there is a clash. The aim of this was two-fold: to see whether hearers do treat I'm sorrys which precede insults/strong criticism (i.e. impolite messages) as non-apologies (to use Kampf's (2009) terminology) as we would expect, and if that is the case, whether this holds true for all hearers.

The findings of this empirical investigation motivate a more theoretical discussion of how we can account for the language users' interpretations of apologies. The main thrust of the paper will suggest that the evidence points in the direction of supporting Jucker \& Taavitsainen's view that speech acts are 'fuzzy concepts' which 'require a prototype approach' (2008:6). In light of the findings here, and previous work on apologies (in particular Murphy, 2015, 2016; Kampf, 2009; Robinson, 2004, 2006), I propose the most salient parameters to account for (non-)canonical apologies. These relate to the identifiability of the offence, the speaker's responsibility for it and the speaker's perceived attitude towards it, amongst other things.

${ }^{1}$ A reviewer makes the helpful point that in political discourse, this phenomenon can be explained by what de Ayala (2001: 163f) calls 'institutionalized hypocrisy'. An institutional frame can compel a speaker to reduce the threat of highly hostile expressions with token politeness. It may well be that this is not simply a feature of institutional talk. 
The structure of this paper is as follows: in section 2, I will review some of the most relevant literature to this study; in section 3, I discuss the methodology which informs the experimental study; in section 4, I highlight the most salient results from the experiment; in section 5, I discuss these results and explain why I think they support the view that apologies (as well as other speech acts) are best considered as prototype entities as opposed to entities defined by static felicity conditions; in the final section, I offer conclusions and suggestions for further work.

\subsection{Literature review}

In this section I will outline papers relating to apologising writ large, on the multifunctional nature of the token (I'm) sorry, and clashes between politeness and impoliteness.

\subsection{Apologising and sorry}

Goffman suggested that apologies see a speaker split herself ${ }^{2}$ in two: a bad half which caused an offence to the apology recipient, and a good half which recognises the offence and seeks to remedy it (Goffman, 1971: 110ff). It is through the production of the apology that the speaker seeks to repair social relations with her interlocutor - in this respect, apologies are performative acts.

Viewing apologies as being performative speech acts, a number of researchers (e.g. Murphy, 2015; Ogierman, 2009; Owen, 1984) have sought to provide felicity conditions for the act of apologising - in other words, criteria which need to be met for an utterance to be treated as an apology. These vary in their detail but they include matters such as: the act being apologised for was carried out by the apologiser (or someone she represents); that the speaker believes the act to be in some way an offence; that the speaker regrets the act in question. These matters will be important when it comes to thinking about why speakers may (or may not) treat an I'm sorry token as a 'proper' apology.

Moving away from what an apology is to how it is commonly carried out, Deutschmann makes the point that 'apologising tends to be accompanied by a limited set of easily identifiable routine formulae' (Deutschmann, 2003: 36). Blum-Kulka \& Olshtain (1984) identify a variety of illocutionary force indicating devices for the speech act of apology, including: I apologise, (I'm) sorry, pardon me, excuse me, and I regret. These may or may not be accompanied with other elements which make the apology more elaborate. Aijmer (1996: 85) finds that utterances containing sorry are by far the most common means of apologising in the LondonLund Corpus. This is also found by Deutschmann in his study of the British National Corpus (2003: 51).

Whilst (I'm) sorry is the most common form of apology, at least in British English, it is not restricted to simply apologising. I'm sorry is frequently used in expressions of sympathy (I'm

\footnotetext{
${ }^{2}$ For convenience, I will refer to speakers using feminine pronouns and hearers with masculine ones.
} 
sorry for your loss as perhaps the go-to instance of this). In noting that I'm sorry occurs in both sympathetic and apologetic utterances, Smith (2008: 35) suggests that this 'leads to a lack of clarity regarding the role of causation in apologies, which in turn creates a variety of confusions and possibilities for manipulation'. It is also one of the reasons that Murphy (2015) suggests that I'm sorry is not an explicit form for apologising, but rather a generalised conversational implicature which by default issues an apology, but otherwise can perform these sympathetic uses, and as I will show later, more challenging functions (see Levinson, 2000). This multifunctionality associated with I'm sorry (which is not evidence in I apologise), is why this study focusses on this form.

\subsection{Non-apologies and verbal formula mismatches}

Kampf (2009) suggests that politicians calculate the costs and benefits to offering apologies in the public sphere. He proposes that in so doing the politician may produce an apology which is in some way evasive since this 'can be useful from the speaker's point of view precisely due to the various meanings that may be assigned to his ambiguous utterance' (Kampf, 2009: 2260). Kampf gives a thorough-going analysis of the ways in which Israeli public figures give nonapologies, i.e. utterances which equivocate when it comes to apologising.

Whilst it may be the case that non-apologies are more prevalent in public discourse, I think it would be wrong to suggest that they do not feature in quotidian conversation - after all, apologisers in everyday life are conducting similar cost-benefits analyses when producing their apologies. I am interested in this paper to see how such so-called non-apologies are reacted to, whether they are, indeed, treated as infelicitous.

Culpeper (2011: 174ff) discusses how conventionalised politeness formulae can precede impolite utterances, giving the paradigm example: 'Could you just fuck off?' where the polite expectations set up by the conventionally indirect (polite) request form clash with the impolite message conveyed by 'fuck off'. He calls examples likes this verbal formula mismatches. Other examples adduced include no offence, and with respect being used before offensive and disrespectful messages respectively. Whilst Culpeper does not draw attention to the use of I'm sorry in possible verbal formula mismatches, it is clear that this polite token can be used to preface impolite expressions. This type of mixed expression is becoming conventionalised, according to Culpeper, such that a hearer can recognised 'the impolite meaning projected by the conventionalised mixed message' (Culpeper, 2011: 178).

In this paper, I propose to explore this by seeing whether hearers treat I'm sorrys in verbal formula mismatches as being apologies (which we would not expect if this impoliteness has become conventionalised). This develops on a paper by Kampf \& Blum-Kulka (2011) into the interpretation of the Hebrew equivalent of I'm sorry. They show that hearers, on the whole, treat I'm sorrys in verbal formula mismatches as being adversarial, rather than apologetic. However, they find a minority of respondents treating such utterances as apologies proper. This study will explore whether the same is true for (British) English, and seek to explain such behaviours. 


\subsection{Methodology}

In order to explore whether or not I'm sorry was interpreted differently when in utterances which would be described by Culpeper (2011) as a 'verbal formula mismatch' or by Kampf (2009) as a 'non-apology', I carried out a questionnaire in which respondents were played recordings of various utterances which began with I'm sorry. Respondents could play the utterance three times and were then prompted to answer a variety of questions relating to the recording. They did this for each of the 16 utterances in the experiment.

\subsection{Test phrases}

The following 16 test phrases were selected - a mixture of 'proper' apologies, expressions of sympathy, possible non-apologies and I'm sorrys which preface a face-attack:

\begin{tabular}{|c|c|c|}
\hline & Test phrase & Suggested type of utterance \\
\hline 1 & I'm sorry I won't be able to come & \multirow[t]{4}{*}{ 'Proper' apologies } \\
\hline 2 & I'm sorry I upset you & \\
\hline 3 & I'm sorry I completely forgot to do it & \\
\hline 4 & I'm sorry you haven't been seen yet & \\
\hline 5 & I'm sorry you won't be able to come & \multirow[t]{2}{*}{ Expressions of sympathy } \\
\hline 6 & I'm sorry to hear that & \\
\hline 7 & I'm sorry about that & \multirow{2}{*}{$\begin{array}{l}\text { Non-apology by blurring the } \\
\text { offence (Kampf, } \\
2265 f f)\end{array}$} \\
\hline 8 & I'm sorry for the mistake & \\
\hline 9 & I'm sorry if I've upset you & $\begin{array}{l}\text { Non-apology by } \begin{array}{r}\text { non- } \\
\text { performativity } \\
\text { 2009: 2262) }\end{array} \\
\text { (Kampf, }\end{array}$ \\
\hline 10 & I'm sorry you feel that way & \multirow{2}{*}{$\begin{array}{l}\text { Non-apology by omitting or } \\
\text { blurring the agent (Kampf, } \\
\text { 2009: 2268f) }\end{array}$} \\
\hline 11 & I'm sorry you've been made to feel that way & \\
\hline 12 & I'm sorry you can't speak to people like that & \multirow[t]{3}{*}{ ?Verbal formula mismatch } \\
\hline 13 & I'm sorry you've pushed me too far & \\
\hline 14 & I'm sorry your behaviour has been appalling & \\
\hline 15 & I'm sorry he is such an arsehole & \multirow{2}{*}{$\begin{array}{l}\text { Verbal formula mismatch } \\
\text { (Culpeper, 2011: 174) }\end{array}$} \\
\hline 16 & I'm sorry you are such an arsehole & \\
\hline
\end{tabular}

Table 1: List of test examples

Each test item is made up of I'm sorry and the apologisable (i.e. the thing that could possibly be being apologised for) only. There is no embellishment of the type often found in everyday apologies, e.g. promise of non-recurrence 'that won't happen again'; offer of repair 'let me pay for a new one', etc. (see Blum-Kulka \& Olshtain, 1984 for more examples). This was done 
so that the focus of the participant is directed towards the use of I'm sorry over and above any additional elements.

The decision to keep the apology token the same (i.e. as I'm sorry) was also a deliberate one elsewhere it has been argued that I'm sorry is a token which performs the apology by default but not explicitly, i.e. it is a generalised conversational implicature (Murphy, 2015). This potential multifunctionality is what is of interest in this paper and this is not shared with explicit apologies like I apologise and I offer my apologies. Moreover, simply saying sorry, without the explicit subject, is typically associated with discourse management matters rather than bona fide apologies (Mattson Bean \& Johnstone, 1994).

Notice that examples 12-16 could felicitously have the connective but between the I'm sorry and what follows; the effect of this would make explicit that there was a contrast/concession between the putative apology and the rest of the utterance ${ }^{3}$. I chose not to include but in these examples as I would be concerned that this conventional implicature ${ }^{4}$ might be seen as the driver behind participants spotting the potential mismatch.

It was felt important to keep the same speaker for each of the phrases to ensure that extraneous variables like speaker gender (cf. Schumann \& Ross, 2010), or how nice the speaker sounded (cf. Ambady et al., 2002 which suggested that 10 second voice samples from doctors were sufficient for participants to come to a view on the warmth or otherwise of the doctor) were not introduced.

In addition, intonation was a consideration. Aijmer (1996: 88) indicates that a 'fall-rise or rising tone was most common in casual apologies' in the London-Lund Corpus, but quoting Lindström that ' $[w]$ ith a low fall the apology tends to sound more genuine and regretful' (Lindström, 1978: 177, quoted in Aijmer, 1996: 89). So that intonation did not 'give the game away' about the possible differences between the test items, the same I'm sorry was used in all 16 examples. The token was produced with a low fall (see Figure 1). In addition, the same gap (or rather lack of one) between I'm sorry and the rest of the utterance was maintained. This was done in order to ensure consistency across all 16 test items. In order that the examples sounded natural, the intonation of the rest of the test item (i.e. everything after sorry) varied.

\footnotetext{
${ }^{3}$ It would also be possible to place but after sorry in examples 1, 3 and 5. The effect would, I think, be similar but this merits further investigation.

${ }^{4}$ I stick to the Gricean view that but carries conventional implicature - i.e. it is part of the agreed word meaning of the lexical item - in this case, of concession or contrast (Grice, 1989: 42ff). Potts (2005: 213ff) suggests that but is not a conventional implicature and Bach (1999) denies the existence of conventional implicatures altogether. These are debates for elsewhere, but that they are being had reinforces my view that it is best to avoid including but in these examples.
} 




Figure 1: The intonation contour of one of the test items (taken using Boersma \& Weenik's (2013) Praat)

\subsection{The questionnaire}

Participants accessed the questionnaire individually online and could complete it at their own pace (but once the questionnaire was opened it had to be completed in one sitting). Each participant was presented with the 16 test phrases one at a time and in a semi-random order, such that like phrases would not appear consecutively (e.g. test phrases $2 \& 9$ amongst others would always be separated by at least two other test phrases).

The respondents were asked to rate each example for how apologetic they thought the speaker was from 0 (not at all apologetic) to 6 (completely apologetic). In addition, participants were asked to consider how bad the speaker felt, from 0 (Doesn't feel bad at all) to 6 (Feels very bad).

After focussing on their views of the speaker's feelings, respondents were then asked to imagine how they would feel following the utterance they heard - from -6 (Completely worse) to 6 (Completely better), with 0 (Neither better nor worse) as the mid-point.

Finally, participants were asked whether or not they thought the speaker was apologising (a forced yes or no choice) and to give a reason for their response (no more than 350 characters). The questionnaire was limited to these 5 questions (generating 80 data points per participant) to avoid informant fatigue (though this was still evident for some participants).

\subsection{The participants}

All participants were native British English speakers and were first year undergraduate students of Linguistics who had not yet had any instruction in pragmatics/semantics. Click-through rates were monitored and those participants who either: did not click play on the extracts at all, or had suspiciously quick response times (i.e. completed all five questions in 15 seconds or less and entered gibberish in the free-response question) were excluded entirely from the results. This left 78 participants - demographic information was not collected as this was not the focus of the study (although given the average undergraduate linguistics class in the U.K., I would venture that the vast majority were female and aged 18-25). 


\subsection{Results}

Table 2 shows the average scores for each of the test items, as well as the percentage of participants who answered 'yes' to the question: 'Is the speaker apologising here?'.

\begin{tabular}{|c|c|c|c|c|c|}
\hline & Test phrase & $\begin{array}{l}\text { Apologetic } \\
\text { (average score /6) }\end{array}$ & $\begin{array}{l}\text { Feels } \\
\text { bad } \\
\text { (average } \\
\text { score /6) }\end{array}$ & $\begin{array}{l}\text { H. feels } \\
\text { worse/better } \\
\text { afterwards } \\
\text { (average } \\
\text { score } \\
\text { between -6 } \\
\text { to 6) }\end{array}$ & $\begin{array}{l}\text { \% who say } \\
\text { the speaker } \\
\text { is } \\
\text { apologising }\end{array}$ \\
\hline 1 & $\begin{array}{l}\text { I'm sorry I won't be able } \\
\text { to come }\end{array}$ & 5.0 & 4.4 & 2.6 & $93.6 \%$ \\
\hline 2 & I'm sorry I upset you & 4.9 & 5.0 & 4.2 & $94.9 \%$ \\
\hline 3 & $\begin{array}{l}\text { I'm sorry I completely } \\
\text { forgot to do it }\end{array}$ & 5.1 & 5.0 & 1.7 & $89.7 \%$ \\
\hline 4 & $\begin{array}{l}\text { I'm sorry you haven't } \\
\text { been seen yet }\end{array}$ & 4.4 & 3.1 & -0.7 & $85.9 \%$ \\
\hline 5 & $\begin{array}{l}\text { I'm sorry you won't be } \\
\text { able to come }\end{array}$ & 4.9 & 4.3 & -3.9 & $93.6 \%$ \\
\hline 6 & I'm sorry to hear that & 3.5 & 4.9 & 3.2 & $46.1 \%$ \\
\hline 7 & I'm sorry about that & 4.3 & 3.0 & 2.9 & $79.5 \%$ \\
\hline 8 & I'm sorry for the mistake & 4.0 & 3.2 & 1.8 & $82.1 \%$ \\
\hline 9 & I'm sorry if I've upset you & 2.8 & 3.5 & 0.8 & $33.3 \%$ \\
\hline 10 & I'm sorry you feel that way & 1.3 & 1.7 & -4.0 & $28.2 \%$ \\
\hline 11 & $\begin{array}{l}\text { I'm sorry you've been } \\
\text { made to feel that way }\end{array}$ & 2.6 & 1.8 & -3.3 & $33.3 \%$ \\
\hline 12 & $\begin{array}{l}\text { I'm sorry you can't speak } \\
\text { to people like that }\end{array}$ & 1.9 & 2.1 & -4.2 & $43.6 \%$ \\
\hline 13 & $\begin{array}{l}\text { I'm sorry you've pushed } \\
\text { me too far }\end{array}$ & 2.1 & 5.4 & -4.6 & $26.9 \%$ \\
\hline 14 & $\begin{array}{l}\text { I'm sorry your behaviour } \\
\text { has been appalling }\end{array}$ & 1.8 & 4.7 & -5.2 & $29.5 \%$ \\
\hline 15 & $\begin{array}{l}\text { I'm sorry he is such an } \\
\text { arsehole }\end{array}$ & 2.3 & 5.1 & 0.9 & $34.6 \%$ \\
\hline 16 & $\begin{array}{l}\text { I'm sorry you are such an } \\
\text { arsehole }\end{array}$ & 1.8 & 4.5 & -4.4 & $29.5 \%$ \\
\hline
\end{tabular}

Table 2: Group (N=78) averages in response to each I'm sorry utterance

Perhaps unsurprisingly, participants view the speaker as more apologetic when saying sorry for more tangible offences (examples 1-4) compared to the less canonical instances (examples 12-16). Indeed, only a minority of participants describe the speaker as apologising in examples 
12-16 - albeit a not insignificant minority, and this is something I will pick up again at length in the next section. The question of the speaker feeling bad gets a relatively high average score for both sets of I'm sorrys - the speaker asserting that the hearer's behaviour has been appalling and potentially upsetting them (ex. 14) is said to feel just as bad on average as when she is apologising for having upset the hearer (ex. 2). It seems that participants believe that she feels bad in one case because she has been wronged and in the other because she has done wrong ${ }^{5}$.

The non-apology examples are also of interest. The two examples of non-apology by blurring the offence (exx.7-8) score quite highly in terms of how apologetic the speaker is viewed as and in both cases more than three-quarters of respondents treat these as apologies. This does not mean that Kampf (2009) is wrong to categorise these as non-apologies - I think if the participants were given more context rather than being left to imagine their own contexts, then these results would likely have been different. What is interesting to note, however, is how these instances of non-apologies contrast to the others where the agent is blurred (ex. 10-11) or there is some form of non-performativity (ex. 9, in this case: conditionality). These nonapologies are received very badly by participants - only a minority state that the speaker is apologising and the group rate her 'apologeticness' very low. It is worth mentioning, however, that some participants give a score of 1 or 2 (even 3 in some cases) for how apologetic the speaker is, even though they go on to answer 'no' to the question of 'Is the speaker apologising?'. This strikes me as curious; I would have anticipated that if a respondent said that they speaker was not apologising then they would have rated her as being not at all apologetic (i.e. a rating of 0). This suggests that there is more to 'doing' an apology than simply being thought of as feeling somewhat apologetic. This is something I will return to in the next section.

Example 5 ('I'm sorry you won't be able to come') was intended as an expression of sympathy when the test materials were written and so I thought it surprising that so many respondents treated this as an apology. I had hoped to say something exciting in light of it that the sympathy sense of sorry was being lost to the apology sense - but then I read the respondents' qualitative comments answering the question of why they thought this was an apology. Rather than hearing this as something like: I'm sad/disappointed to hear that you are unable to make the party/event/etc., virtually all the respondents reported that the person was apologising because they weren't invited/weren't allowed/were banned from(!) coming to the event. I, therefore, will not dwell on example 5, but I mention it explicitly as a reminder that it is always worthwhile ensuring that participants are answering what you think they are answering.

The other 'sympathy' example (6: 'I'm sorry to hear that') does see the anticipated drop in responses suggesting that this is an apology. Just over half did not see this as an apology, and

${ }^{5}$ There was a cluster of respondents $(\mathrm{N}=6)$ who rated the speaker in ex. 16 ('I'm sorry you are such an arsehole') as not feeling bad at all (i.e. a score of 0 ). In their comments, they said that the speaker was not apologising and that they did not have a need to because it was 'just banter' (or words to that effect). It is beyond the scope of this paper to discuss banter or jocular mockery any further, but others in this special issue do (see papers by Aijmer and Beeching). 
the ratings for the speaker feeling bad were high (suggesting the idea that the speaker feels bad for the recipient). It is also interesting to note that such expressions of sympathy were rated as potentially making the participant feel better. Of those who did say example 6 was an apology, there were a few comments which suggested that it would be an apology if the speaker had done something wrong. There was a particularly interesting comment along these lines of:

It's the sort of thing someone says when they've been caught out and don't want to say sorry properly.

Comments like this - particularly invoking the idea of doing a speech act 'properly' - suggest that some respondents may accept that a speaker is apologising, but may be, in some way, dissatisfied with it. They may view the speaker as 'going through the motions' (cf. Wachtel, 1980). This sort of metapragmatic comment supports the view which I will outline in the next section, that there is a continuum of performativity - it is not simply the case that someone apologises or not, but there is a spectrum of apology-like behaviour.

This also has a bearing on the findings relating to feeling better/worse as a result of the utterance. Take a comment in response to example 4 which the participant agreed was an apology:

At the doctors they just say this but you know they aren't really bothered and you probs aren't gonna get seen any time soon

So whilst an apology might have the intention of repairing damaged relations, it need not necessarily fulfil that goal to still be thought of as being an apology.

\subsection{Discussion}

In this section, I will propose an account for the issues which emerge from the results just discussed, as well as previous studies into apologising both in everyday life and political discourse.

Firstly, I offer a summary of some of the matters that need to be taken into consideration:

1) People do not always agree on what counts as an apology

2) Even verbal formula mismatches (i.e. where I'm sorry precedes some sort of impolite comment) are treated by some as apologies proper

3) There is a spectrum of how apology-like certain actions are

So how do hearers make judgements about whether the use of I'm sorry is performing the speech act of apology? And why do these judgements vary between speakers? Here is where I believe the notion of the prototype is useful.

Jucker \& Taavitsainen suggest that "speech acts are fuzzy concepts" which "can be analysed 
in relation to neighbouring speech acts, to their changing cultural groundings, and to ways in which they are realised" and that their fuzziness "requires a prototype approach; individual instances vary in their degree of conformity to their prototypical manifestations and sometimes the group identity is only vague" (Jucker \& Taavitsainen, 2008:6). I believe modelling speech acts as prototype elements gives further explanation for why some sorrys are viewed as more apologetic than others, and in different ways by different hearers.

This is not, however, the first time that apologising has been considered from a prototype perspective. Jeffries (2007:63ff) proposes fourteen parameters along which the utterance can be more or less like an apology. These parameters include: type of expression used, tense of the utterance, person used therein, seriousness of offence, the responsibility of the apologiser, etc. I believe that some of these parameters are important in deciding whether an act is more or less like an apology, but others less $\mathrm{so}^{6}$.

For instance, if we think about the tense of an utterance, this can have not just an effect on whether it is a central exemplar of an apology, but can prevent it being an apology at all. I was sorry and I will be sorry, for instance, represent changes in tense from the simple present, which Jeffries' views as the most prototypical way of apologising, but change the act in question from being an apology to being a report and a commitment respectively. Even changing the phrasing to something like I have said sorry is still likely to be treated as a non-apology (cf. Kampf, 2009). Moreover, changing the illocutionary force indicating device to the explicit apologise and manipulating the tense is still problematic (I have apologised still conveys a report of an apology). So it is for this reason that I will argue that we need to remove parameters related to form from the discussion of prototypicality of the act.

That aside, Jeffries suggests that an apology which is accepted is more prototypical than one which is rejected. Indeed, she suggests that 'many of the other [prototypical] features may be lacking if the wronged person is willing to accept the communicative act as an apology' (Jeffries, 2007:62). I am minded to agree that uptake here is important; in the questionnaire design I explicitly included a question on whether or not the respondent believed the speaker was apologising to get at whether the utterance was treated as an apology. What I would say, however, is that, in interaction, the central exemplars of apology would not have explicit acceptance of the apology as the uptake but rather, as Robinson (2004) argues, the preferred response of rejecting the need to apologise. In addition, absence of uptake or even rejection of the apology does not mean that an apology has not happened; unlike, for instance, a lack of uptake to a bet means that a bet has not been entered into. Instead, a rejection of an apology simply means that the intended perlocutionary effect has not been realised - this naturally

${ }^{6}$ The full list of parameters is as follows: i) IFID used; ii) tense/aspect of IFID; iii) person of the verb; iv) contents of the following text; v) level/seriousness of the 'wrong'; vi) timing of the 'wrong'; vii) sincerity of the apologiser; viii) addressee of the apology; ix) responsibility of the apologiser; $\mathrm{x}$ ) impetus (whether the apology was solicited or not); xi) best interests of the apologisee; xii) equality of apologiser/apologisee; xiii) whether the apologiser intends the act to be an apology; xiv) whether the apology is accepted. 
makes the apology in question less prototypical, but does not mean that it has not been performed. This is an important distinction to bear in mind, especially in light of what participants said earlier - that a speaker might failed to offer a 'proper' apology, but they still might view her as apologising.

In the rest of this section, I will outline what I think to be the most important parameters which help discern a more prototypical apology from a less prototypical one. The first two of these parameters are informed by the results from this paper (and to a lesser extent parameter 3), the rest are adduced in light of previous work on apologies.

\subsection{Parameter 1: Identifiability of the offence}

$\leftarrow$ Less prototypical

Dubious

\section{Effortful}

More prototypical $\rightarrow$

Straightforward

If an offence is easily identifiable, either because it comes immediately after the offence, a complaint, or is referenced by the apologiser, then the apology is a more central exemplar. It is clear how examples 1-5 and 8 would fall on the more prototypical end of the spectrum - the apologiser references (to a greater or lesser extent) the apologisable. It is also conceivable that when responding to example 7 (I'm sorry about that) hearers imagined a context in which the apology arose and that involved a complaint or the performance of an offence.

Offence identification might be considered more effortful in cases not discussed so far in this paper such as when a speaker uses an apology token to seek clarification. It could be that in saying I'm sorry (usually with rising intonation) as a means of other-initiated other-repair (Levinson, 1983: 340-1) the apologiser believes they are at fault because she was not listening carefully enough, but equally the seeking of repair work could be taken as a complaint levelled at the interlocutor for not being clear (see Robinson, 2006 and Aijmer, 1996: 102-3). It is for this reason that I would suggest that offence identification in such cases is more effortful.

If the attempt to identify the nature of the offence results in only a dubious offence or something which might actually be construed as an offence committed by the hearer, then the apology in question is least prototypical. This end of the spectrum would cover things like: i) a situation where a speaker says sorry when her toe has been run over by someone dragging a suitcase in a busy train station; ii) apologies which preface disagreement or contradiction; iii) ironical uses of the apology.

I propose that one of the ways for the analyst to assess the ease of identifiability of the offence is to consider whether or not it forms part of the at-issue content of the utterance, that is to say the information which 'hearers will expect [...] to constitute the speaker's central message' (Potts, 2015: 168). In cases where the offence is easily discernible, it should not form part of the at-issue content, it should be backgrounded. Tonhauser (2012) proposes a variety of ways to discern the at-issue content; unfortunately, none of these are directly applicable when it comes to looking at performatives. Instead, I suggest a development which I will call the 
'Really? Test'. We can take one of the test examples and intuit how the discourse would continue if the apologisee were to respond by saying with some incredulity: 'Really?'. For instance (test example 2):
A: I'm sorry I upset you
B: Really?
A: Yes, I am sorry/\#Yes I did upset you

In this case, what is at-issue (i.e. the main point of the utterance) is the apology itself and not the offence triggering the apology. Contrast that with example 14 which when subjected to the Really? Test would most likely (for me at least) generate the following:
A: I'm sorry your behaviour has been appalling
B: Really?
A: \#Yes, I am sorry/Yes, it has been appalling

In this case, the I'm sorry is not the main focus of the utterance but the following facethreatening/attacking act. As such, it is far more effortful to try to work out what the speaker could possibly be apologising for, if the I'm sorry is to be treated as a bona fide apology.

The three points that I have suggested (straightforward, effortful, dubious) on the continuum are not the only places at which an apology might be found; it is possible that some offences are more straightforwardly identifiable than others, for example. Not only that, different speakers - based on their own experiences - are likely to gauge the identifiability of offences differently. One of the respondents, for instance, suggests that in the case of I'm sorry you are such an arsehole that the offence being apologised for is the imminent insult, but contra Culpeper (2011: 175) who suggests that the polite token is blatant lip-service being paid to politeness:

They probably don't want to be mean but they might feel like they have to.

Others, and likely particularly those who did not view this as being an apology, would agree with Culpeper here - it is highly suspect for the speaker to be apologising for the imminent face-attack; the use of I'm sorry here may well be a form of lip-service. The fact that languageusers come to different views of these utterances is all the more reason to consider speech-acts as prototype entities, since we would expect this form of categorisation to be highly dependent on personal experience and individual cognitive processes.

\subsection{Parameter 2: Speaker's perceived attitude toward the offence}

$\leftarrow$ Less prototypical

Feels there was no offence

against the recipient
More prototypical $\rightarrow$

Feels indifferent $\quad$ Feels bad (esp. for the recipient) 
Deciding on how a speaker feels about the offence for which she is apologising is naturally fraught with difficulty, but judging the apologiser's sincerity is something which recipients do. Hearers may judge whether the apologiser feels bad about the offence on the basis of, among other things, her body language and facial expressions. For instance, she may struggle to maintain eye contact (Modigliani, 1971) or she might engage in self-touching behaviours (Freedman \& Bucci, 1981; LeCompte, 1981) - all signs given-off, to use Goffman's (1959) terminology, which indicate the speaker's feeling negative emotion.

But as we have seen from the results of this task, the words used to produce an apology will also affect how the recipient perceives the speaker's attitude toward the offence. I'm sorry you feel that way receives an extremely low rating when it comes to how bad the speaker is believed to feel and is viewed as an apology by only a third of speakers. By pushing the responsibility of the offence on to apologise, the speaker at the very least feels indifferent about what she has done to cause upset or feels that she has not committed an offence at all.

I suggest that this sense of feeling bad should especially be directed towards the recipient of the apology. I say this in light of examples like 13, I'm sorry you've pushed me too far. Here, respondents rate the speaker as feeling bad (indeed, the highest rating in this category across all 16 test utterances) but only the minority believe the speaker to be apologising. I suggest that participants are rating the speaker as feeling bad, not because of anything she has done, but because she has been made to feel that way. As such, she does not feel bad for the recipient of the 'sorry' token, but because of the recipient. This would, therefore, be a less prototypical example.

A final, perhaps even less prototypical scenario, would be apologies which are prompted only by the intervention of a third party, where certainly the apologiser but also possibly the apologisee feels no offence has occurred. This type of example was highlighted in Murphy (2015: 181) where an overhearing mother reprimands her son so that he apologises, despite neither apologiser nor purported offended party believing there had been an offence.

\subsection{Parameter 3: Speaker's apparent responsibility for the offence}

\section{$\leftarrow$ Less prototypical}

Apologiser's transportable identity not involved
More prototypical $\rightarrow$

T.I. indirectly involved T.I directly involved

Apologies which are for offences which the apologiser committed will be most prototypical. Examples like I'm sorry your behaviour has been appalling are interesting - if we view the offence as being that the speaker is having to say something face-attacking (as was identified in a roundabout way by some participants), then the recipient could be argued to carry some responsibility that this offence has come about. (Whether a recipient would likely acknowledge this in the moment is a debate for another day, but again, this source of inter-speaker variation is another reason why a prototype approach has its merits). 
The inclusion of the notion of 'transportable identity' in this parameter (Zimmerman, 1998) is mostly inspired by work on historical apologies, i.e. apologies aimed at bringing about reconciliation between a government/company/public body and a group of wronged parties following an extended period between the offence and the apology. A number of studies (Marrus, 2006: 13; Tavuchis, 1991:71ff) discuss the fact that these apologies are treated with scepticism. The reasons for this scepticism are manifold, but the most frequently cited aspect: the apologies are most often given by people neither directly nor indirectly responsible for the action. Given that, I think it makes sense to include this parameter in the calculation of the prototype apology.

Here the different identities which speakers occupy during talk - discourse, situational and transportable (Zimmerman, 1998) - will be useful in explaining how responsibility for the offence can be viewed on a scale. Discourse identities are those which are assumed by participants 'as they engage in various sequentially organized activities' (Zimmerman, 1998:90). For our purposes, the important discourse identities for the act of apologising are apologiser and apologisee. Situational identities are brought into being by being a participant in a certain activity, so imagine example 4 (I'm sorry you haven't been seen yet) did take place in a doctor's surgery: receptionist_patient identities would be invoked in this scenario. Transportable identities, however, are the aspect which I argue affect the prototypicality of the apology. Zimmerman suggests that transportable identities are "latent identities which 'tag along' with individuals as they move through their daily routines" (ibid.). Zimmerman suggests visible indicators such as race, gender, age, etc. as forming part of a transportable identity. To those visible indicators we can also add issues related to participants' previous experience of the individual in question - whether she is a crashing bore, owes money to a participant, or perhaps of most relevance to us, has previously been involved in wrongdoing constituting an offence.

In the most prototypical cases, where the speaker has a discourse identity of apologiser, her transportable identity of 'offender' will also be directly oriented to in the action of apologising. Slightly less prototypical are cases such as a parent apologising for their child, or a receptionist apologising that the doctor is running late. Here transportable identity is still relevant (but less so) because the apologiser's identity as someone who is bringing up or organises the schedule of the offender is what is oriented to.

The least prototypical apologies are ones which do not involve the transportable identity at all, such as historical apologies. Here the apologiser is not identified as being the offender who was involved (either directly or indirectly) in the acts discussed in the apology. She is able to apologise by virtue of her discourse identity (of an apologiser) and, most importantly, her situational identity of 'politician called on to apologise' and who represents her predecessors and the nation.

\subsection{Parameter 4: Identity of the recipient}


This parameter concerns the status of those who the apology is directed at. Here we consider the inverse aspect of transportable identity, where the individual has had a wrong done to them. The most central exemplars of apology will have the offended party as a/the recipient - in these cases the apologisee's transportable identity as a 'victim' (for want of a better term) is oriented to.

Less prototypical are cases where the recipient of the apology is a close relation or friend of the victim - in these instances the offended party is either absent for some reason, but it is conceivable that the apology could be 'passed on' to the relevant party. Transportable identity remains relevant because it is their association with the transgressed party which is involved in the apology.

The most peripheral cases are where a group containing neither the victims themselves, nor close relatives is the recipient of the apology. These apologies are usually for historical transgressions. Here transportable identity is not at issue, since these institutionally recognised representatives of the offended party have not been personally (either directly or indirectly) wronged and are recipients by virtue of their discourse identities (as apologisees) and situational identities (formal and/or legal recipients).

\subsection{Parameter 5: Nature of the uptake}

$\leftarrow$ Less prototypical

None
(Rejection/Question sincerity or quality)
More prototypical $\rightarrow$

Preferred response

Finally, we come to uptake. Since this study looked only at reactions to the I'm sorry stimuli, rather than oral responses, this parameter is suggested in light of work found in Robinson (2004) and Murphy (2016).

The most prototypical apologies have uptake which takes the form of the preferred responses (in conversation analytic terms) of rejecting the need to apologise or minimising the offence. The most peripheral apologies I suggest are ones which have no uptake. This is because no uptake usually comes about as a result of the recipient being absent at the time the apology; in addition, having no uptake means overhearers cannot judge how the apology has been interpreted by the recipient. Between these we have outright rejections and recipients questioning the sincerity or quality of the apology. I place these here because they occur more frequently than does no response at all, but I do not suggest that one of these responses is more prototypical than another. 


\subsection{Conclusion}

In this paper, I have shown that some language users treat non-canonical instances of I'm sorry as apologies proper. Rather than seeing examples of I'm sorry before face-attacks as a means of ramping up the impoliteness of the utterance as a whole, a number see its use as a way of attenuating the threat which is to follow. Treating these examples - and others which might be interpreted as merely expressing sympathy - as apologies, we were left with a puzzle of how to account for this; since a usual felicity condition approach would likely miss these examples (and also would fail to explain the fact that the majority of speakers reject these as being apologies).

The solution I proposed to this was, following Jucker \& Taavitsainen (2008), to consider speech acts as fuzzy concepts and I suggested parameters along which an utterance could be considered more or less prototypically apologetic. A less-than-prototypical apology might instead be a prototypical example of an expression of sympathy, which may be viewed as a neighbouring speech act.

Aside from helping to account for situations in which language users disagree on whether an utterance is a 'proper' apology, it also requires the personal experiences of those language users to be brought to bear in this decision-making process. This applies not only to where on each of the parameters' scale of prototypicality a language user places an instance of apology, but also to what weighting they give each parameter when it comes to judging the quality of an apology. A limitation of this study has been its focus on I'm sorry as a means of apologising. This is, by no means, the only way that speakers apologies - indeed Mills (2003) suggests that there are countless ways to apologise. It may well be that language users apply these same parameters on apologetic utterances which do not include a more or less explicit token of apology. This would merit further investigation.

Further work on how users react to mismatching im/politeness is required to see, amongst other things, how strong the influence of prosody is. It may be possible to exploit ongoing developments in the use of event-related potentials in neurolinguistics and experimental pragmatics which show up extra processing effort to see whether these clashes take longer to process when usual apology intonation is used versus a more marked prosodic pattern.

\section{References}

Aijmer, Karin, 2015. "Will you fuck off please" The use of please by London teenagers. Pragmática Sociocultural/Sociocultural Pragmatics 3. 127-149.

Aijmer, Karin. 1996. Conversational routines in English: Convention and creativity. Harlow: Longman.

Ambady, Nalini, Debi LaPlante, Thai Nguyen, Robert Rosenthal, Nigel Chaumeton \& Wendy Levinson, 2002. Surgeons' tone of voice: A clue to malpractice history. Surgery 132. 5-9. 
Bach, Kent, 1999. The myth of conventional implicature. Linguistics and Philosophy 22. 327366.

Blum-Kulka, Shoshona \& Elite Olshtain, 1984. Requests and apologies: A cross-cultural study of speech act realization patterns (CCSARP). Applied Linguistics 5. 196-213.

Boersma, Paul \& David Weenink, 2013. Praat: doing phonetics by computer [Computer program]. Version 6.0.10, retrieved 12 January 2016.

Culpeper, Jonathan, 2011. Impoliteness: Using language to cause offence. Cambridge: Cambridge University.

Deutschmann, Mats, 2003. Apologising in British English. Umeå: Umeå University Press.

Freedman, Norbert \& Wilma Bucci, 1981. On kinetic filtering in associative monologue. Semiotics 34. 225-249.

Goffman, Erving, 1971. Relations in public: Microstudies of the public order. New York: Basic Books.

Goffman, Erving, 1959. The presentation of self in everyday life. New York: Anchor Books.

Grice, Paul, 1989. Studies in the way of words. Cambridge, MA: Harvard University Press.

Jeffries, Lesley, 2007. Journalistic constructions of Blair's 'apology' for the intelligence leading to the Iraq War. In: Sally Johnson \& Astrid Ensslin (eds.), Language in the media, 48-69. London: Continuum.

Jucker, Andreas \& Irma Taavitsainen, 2008. 'Speech acts now and then: Towards a pragmatic history of English'. In: Andreas Jucker \& Irma Taavitsainen (eds.), Speech acts in the history of English, 1-23. Amsterdam: John Benjamins.

Kampf, Zohar, 2009. Public (non-) apologies: The discourse of minimizing responsibility. Journal of Pragmatics 41. 2257-2270.

LeCompte, William, 1981. The ecology of anxiety: Situational stress and rate of selfstimulation in Turkey. Journal of Personality and Social Psychology 40. 712-721.

Leech, Geoffrey, 2014. The pragmatics of politeness. Cambridge: Cambridge University Press.

Levinson, Stephen, 2000. Presumptive meanings: The theory of generalized conversational implicature. Boston, MA: MIT Press.

Levinson, Stephen, 1983. Pragmatics. Cambridge: Cambridge University Press.

Marrus, Michael, 2006. Official apologies and the quest for historical justice. Toronto: Munk Centre for International Studies.

Mattson Bean, June \& Barbara Johnstone. 1994. Workplace reasons for saying you're sorry: Discourse task management and apology in telephone interviews. Discourse Processes 17. 59-81.

Modigliani, Andre, 1971. Embarrasment, facework and eye contact: Testing a theory of embarrassment. Journal of Personality and Social Psychology 17. 15-24.

Murphy, James, 2016. The status of apologies by politicians at public inquiries. Pragmatics \& Society 7. 595-617.

Murphy, James, 2015. Revisiting the apology as a speech act: The case of parliamentary apologies. Journal of Language and Politics 14. 175-204.

Ogiermann, Eva, 2009. On apologising in negative and positive politeness cultures. Amsterdam: John Benjamins.

Owen, Marion, 1983. Apologies and remedial interchanges: A study of language use in social interaction. Berlin: Mouton. 
Potts, Chris, 2015. 'Presupposition and implicature'. In: Shalom Lapin \& Chris Fox (eds.), The Handbook of Contemporary Semantic Theory, $2^{\text {nd }}$ edition, 168-202. Oxford: Wiley-Blackwell.

Potts, Chris, 2005. The logic of conventional implicatures. Cambridge: Cambridge University Press.

Robinson, Jeffrey, 2006. Managing trouble responsibility and relationships during conversational repair. Communication Monographs 73. 137-161.

Robinson, Jeffrey, 2004. The sequential organization of 'explicit' apologies in naturally occurring English. Research on Language and Social Interaction 37. 291-330.

Schumann, Karina \& Michael Ross, 2010. Why women apologize more than men: Gender differences in thresholds for perceiving offensive behavior. Psychological Science 21. 1649-1655.

Smith, Nick, 2008. I was wrong: The meanings of apologies. Cambridge: Cambridge University Press.

Tavuchis, Nicholas, 1991. Mea culpa: A sociology of apology and reconciliation. Stanford: Stanford University Press.

Taylor, Charlotte, 2016. Mock politeness in English and Italian: A corpus-assisted metalanguage analysis. Amsterdam: John Benjamins.

Tonhauser, Judith, 2012. Diagnosing (not-)at-issue content. Proceedings of Semantics of Under-represented Languages of the Americas 6. 239-254.

Wachtel, Tom, 1980. Going through the motions. Journal of Linguistics 16. 85-88.

Zimmerman, Don, 1998. 'Identity, context and interaction'. In: Charles Antaki \& Susan Widdicombe (eds.), Identities in talk, 87-106. London: Sage. 